\title{
Changes in Sweet Potato Cookies During Storage
}

\author{
Osibanjo A. ${ }^{1, *}$, Bamiro O. ${ }^{2}$, Henshaw F. ${ }^{2}$, Awonorin $\mathrm{S}^{2}$ \\ ${ }^{1}$ Federal Institute of Industrial Research, Oshodi (FIIRO), Lagos State, Nigeria. \\ ${ }^{2}$ Federal University of Agriculture, Abeokuta (FUNAAB), Ogun State, Nigeria.
}

How to cite this paper: Osibanjo A., Bamiro O., Henshaw F., Awonorin S. (2020) Changes in Sweet Potato Cookies During Storage. International Journal of the Science of Food and Agriculture, 4(3), 256-261.

DOI: 10.26855/ijfsa.2020.09.005

Received: June 16, 2020

Accepted: July 12, 2020

Published: August 4, 2020

*Corresponding author: Osibanjo A., Federal Institute of Industrial Research, Oshodi (FIIRO), Lagos State, Nigeria.

Email: goldenfavour2000@yahoo.com

\begin{abstract}
This study was done to determine the shelf stability and quality changes in sweet potato cookies during a storage period of 12 weeks. The cookie samples were packed and sealed in bi-axially oriented polypropylene (BOPP) sachets, stored under tropical ambient conditions, along with a commercial brand of wheat cookies which served as the control. Samples were withdrawn for analyses at 2 week intervals and quality parameters monitored were weight, moisture content, peroxide value, texture in terms of force at peak and deformation. Results showed that the sweet potato cookies were comparable in quality and stability and probably even better than the control during storage. Change pattern in the measured parameters were also found to be similar in both samples. Changes recorded over the storage period were weight gain of $4.6 \%$ and $9.2 \%$, moisture gain of $4.4 \%$ and $2.5 \%$, decrease in force at peak of $80.8 \%$ and $73.2 \%$, increase in deformation of $69.0 \%$ and $82.1 \%$ in the test and control samples respectively. Peroxide value in both samples decreased during storage, with initial and final figures well below the maximum acceptable standard limits. This shows the promising potential of sweet potato as a suitable alternative to wheat in the production of cookies. The adoption of this finding can enable conservation of valuable foreign reserves and ultimately lead to expanding utilization and value addition to sweet potato.
\end{abstract}

\section{Keywords}

Shelf stability, Storage period, Sweet potato cookies, Quality parameters

\section{Introduction}

Cookies are baked flour based pastry confectioneries. They are conventionally made from the bread wheat (Triticum aestivum) and generally accepted as snacks and convenient foods [1]. Basic materials for cookies are wheat flour, sugar, fat, leavening and flavouring agents. Wheat, however, is not native to Nigeria and the Country has been unable to produce enough to meet her need as a result of climatic incompatibilities [2]. Nigeria has been reported to be only about 2.4\% sufficient in wheat production [3] and has had to rely on importation from other countries such as USA, Canada and Australia. With the escalating foreign exchange involved in wheat importation, valued at N635 billion [4] and the need to curtail it, it has become urgently necessary to look inwards to find suitable replacements for the foreign wheat.

Sweet potato (Ipomoea batatas) is a tuberous root crop belonging to the Family Convolvulaceae. Though of South American origin, it is locally grown, readily available and relatively cheap in Nigeria [5]. It is a nutrient rich crop, reported to have values better than other common root crops and even fruits [6]. With an annual production figure of about 3.92 million tonnes [7], Nigeria is the largest producer in Africa and second globally after China, however, the crop is not put to much local use, compared with other tubers [8], [9].

This work, therefore, studied changes in sweet potato cookies, compared with conventional wheat cookies which served as the control, during a twelve week storage period at tropical ambient conditions. The ultimate aim is to determine the suitability of sweet potato flour as an alternative to wheat in cookie production. 


\section{Materials and Methods}

This study was carried out at the laboratories of the Federal Institute of Industrial Research, Oshodi (FIIRO) in Lagos, Nigeria. The test cookies were produced from a mixture of sweet potato flour, fat, sugar, water, milk and baking powder, using a Creaming method [10] to form a pastry dough which was flattened out, with a roller and cut into desired round shape with a cutter. Baking was done at $150^{\circ} \mathrm{C}$ for $30 \mathrm{~min}$, followed by cooling, sealing and packing in BOPP packages of $0.5 \mathrm{~mm}$ thickness. The commercial brand that served as control was obtained from the manufacturer's retail outlet. The samples were kept on the shelf, under tropical ambient conditions (of $27^{\circ} \mathrm{C}$ temperature and $75 \%$ Relative Humidity) for 12 weeks and withdrawal for analyses done at 2 week intervals. Parameters monitored were 1) Weight (g), 2) Moisture content (\%), 3) Force at peak (N), 4) Deformation (mm) and 5) Peroxide value (meq/kg). Weight readings were taken using a laboratory scale (CE-410I, Camry Emperors). Moisture content was analysed by oven drying according to the standard procedures of AOAC [11]. The texture parameters of Force at Peak and Deformation were determined by running a breaking test using a computerized Universal texture testing machine (Testometric 500) at a speed of 30mm/min while Peroxide value was done by the method of [12] Values of the parameters obtained over time were plotted as line graphs using Microsoft Excel, 2015 version and are as presented.

\section{Results and Discussion}

The results from this study are presented in Figures 1-5.

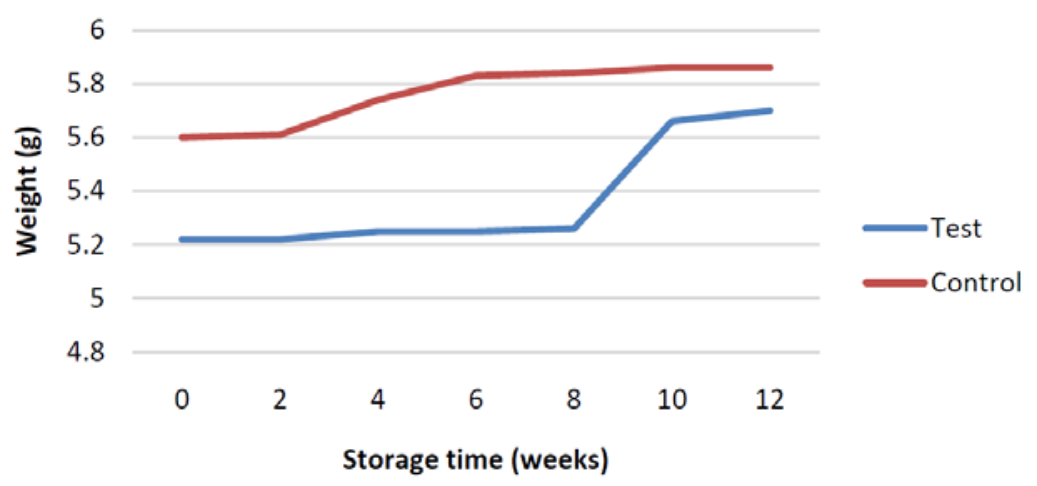

Figure 1. Weight Changes.

Weight readings and changes during the 12 week storage period are presented in Figure 1. From this, it can be observed that the test cookies were slightly lighter in weight than the control, though the difference between both samples became reduced towards the end of the storage period. Weight gain during storage was from 5.60 to $5.86 \mathrm{~g}(4.6 \%)$ in the control and from 5.22 to $5.70 \mathrm{~g}(9.2 \%)$ in the test cookies, showing that the test cookies had a double weight gain compared with the control. The cookie content and package could possibly be responsible for this observation. The control contains some other additives and improvers and also probably had a more protective package, compared with the test sample. Gain in cookie weight as they absorb moisture during storage was also reported by Manakkal [13].

About 2-6 weeks storage time seemed to be critical for the control (when changes in weight were more prominent), while 8-10 weeks seemed critical for the test sweet potato cookies.

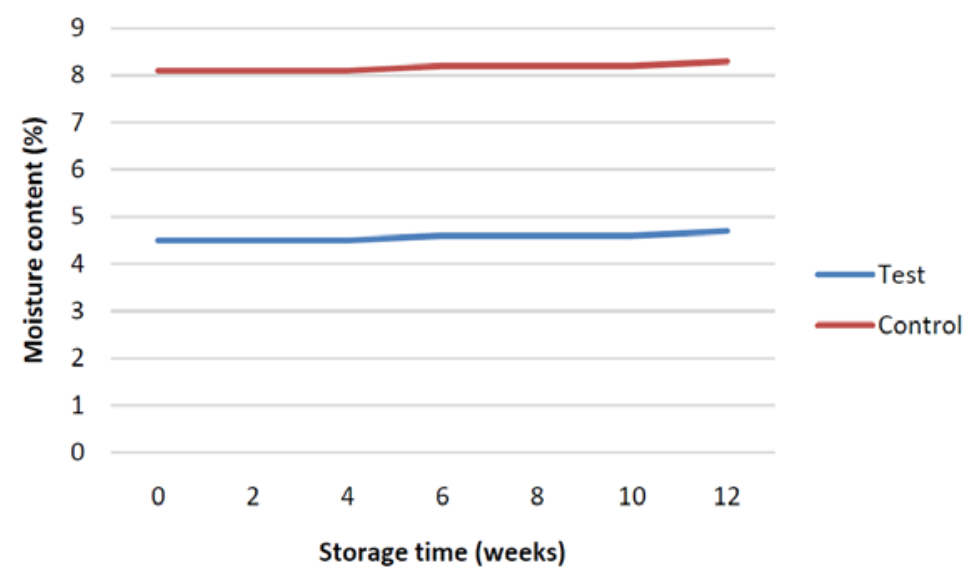

Figure 2. Moisture Changes. 
Moisture content of the cookie samples and changes during the 12 week storage period are presented in Figure 2. The test cookie had about half the moisture of the control (as observed also with weight values in Figure 1), exhibiting as firmness, crispness, freshness or crunchiness which are attributes desired in pastries and which can also help to maintain shelf quality. Moisture content increased from $4.5 \%$ to $4.7 \%$ and from $8.1 \%$ to $8.3 \%$, giving a gain of $4.4 \%$ and $2.5 \%$ in the test and control samples respectively. The nearly straight lines of the moisture graphs shows minimal changes during storage, the moisture gain was also same and a similar pattern was observed in both samples. This tends to suggest the adequacy of the packages to provide barrier to moisture uptake by the cookies. BOPP has been reported to be a good moisture and water vapour barrier, in addition to having other benefits [14]. The issue of water activity (Aw), which is the thermodynamic availability of water for physico-chemical processes and microbial activities, however also needs to be considered and maybe of significance more than just the absolute moisture content.

The physical structure of a food product is often altered by changes in Aw due to moisture gain, resulting in phase transition from the glassy to the rubbery state [15]. Hardly any moisture change was observed in soft cookies during storage yet firming and grainess, which are an indication of quality reduction, occurred as a result of sucrose recrystallization within the cookie [16]. In another study, no increase in Aw was reported for the first 36 days and thereafter remaining constant up to 144days of storage of sweet biscuits from wheat flour/potato starch, however, biscuit hardness increased with attendant reduction in texture sensory scores, probably as a result of starch retrogradation facilitated by increased moisture in the biscuit [17].

Water activity, therefore, is an important factor and with minimal moisture gain during storage, reduction in sample quality can still occur, in this study exhibiting as softening of the cookies. Physically, the samples looked good but they were no longer as crisp as when freshly baked.

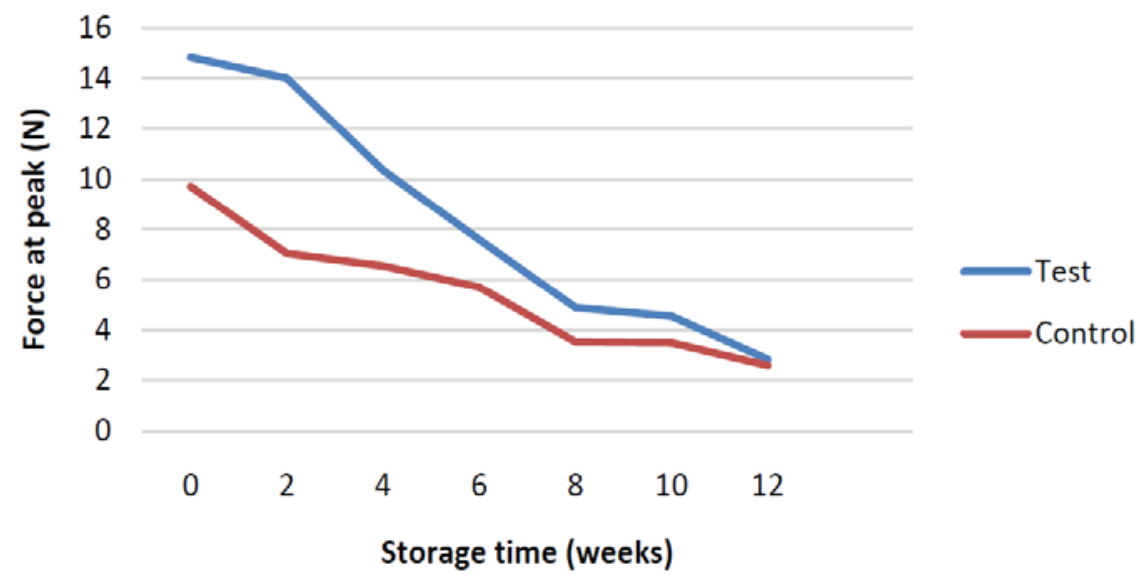

Figure 3. Changes in Force at peak.

The force at peak (in $\mathrm{N}$ ) is a measure of pressure build up on the cookie sample just before breaking and is an indication of the softness or hardness of the sample. Force at peak readings and changes recorded over the 12 week storage period are presented in Figure 3. From these, it can be observed that the test cookies had higher Force at peak values than the control, indicating a firmer or more dense texture, though a similar change pattern was observed in both samples. There was a stepwise decline in force at peak throughout the storage period, from 9.7 to $2.6 \mathrm{~N}(73.2 \%)$ in the control and from 14.83. to $2.85 \mathrm{~N}(80.8 \%)$ in the test cookies, showing a higher reduction in the test cookies on the long run. With different values at the start of the study, both samples had almost the same reduced force at peak value at the end. This shows a decreasing strength to resist breaking, as a result of softening of the cookies, caused by moisture gain and water activity and ultimately indicates a reduction in quality. Texture is an important sensory attribute in food products and the loss of desired texture leads to a loss in product quality and a reduction in shelf life [18]. The rather high temperature and relative humidity of the storage environment $\left(27^{\circ} \mathrm{C}\right.$ and $75 \%$ respectively) recorded in this study, which is typical of tropical coastal areas, can also enhance rapid textural quality reduction.

According to Katz and Labuza [15], moisture pickup causes crisp hard baked, fried puffed or extruded (glassy) foods to become soft, due to the plasticization of carbohydrate polymers and entering into the rubber zone.

Significant changes in textural attributes of some stored samples of commercial cookies have been expressed as a function of relative humidity of the storage environment [19]. Reduction in texture and crispness of fibre rich cookies, as well as the control used, stored in different packaging materials over a 90 day storage period was also reported [20]. All these findings tend to suggest that moisture content of cookie and water activity, appropriate packaging as well as storage environment conditions are the crucial areas of intervention to address the issue of textural changes and to maintain product quality. 


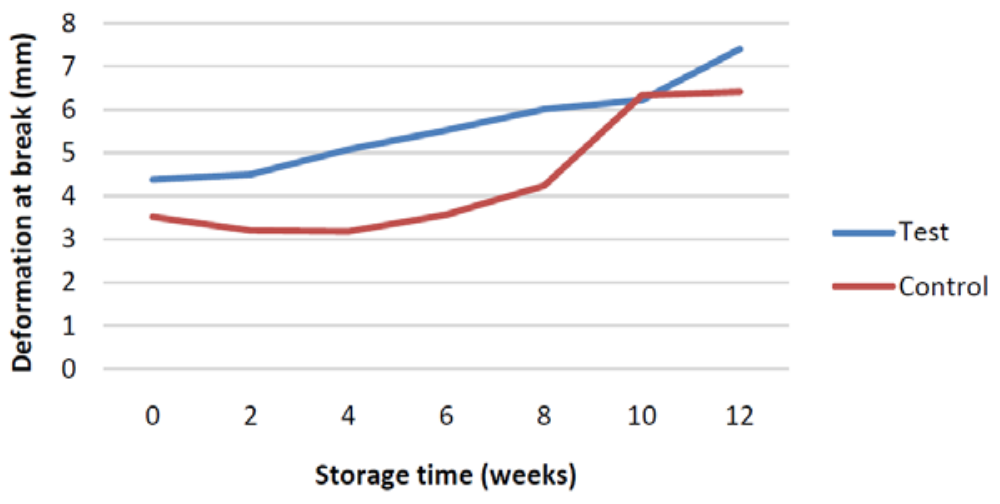

Figure 4. Changes in Deformation.

Deformation at break, in mm, which is the distance travelled at the breaking point of the cookie sample and changes during the storage period are presented in Figure 4. It can be observed that the test cookie had higher deformation at break values than the control. This tends to suggest a chewy kind of texture in the test sweet potato sample, making the break to linger unlike a crunchy texture in the wheat control, giving a neat break. Over the 12 week storage period, however, deformation values increased from 3.52 to $6.41 \mathrm{~mm}(82.1 \%)$ in the control and from 4.38 to $7.40 \mathrm{~mm}$ (69.0\%) in the test sample, showing that on the long run increase in deformation values was more in the control. The increasing values showed that as storage progressed, breaking took place over a longer distance and is an indication of reduced freshness. There was, however, a crucial point at about 10 weeks of storage when both samples had almost same deformation value. Water activity, (Aw) or the energy status of the water in the cookies still seems to be the likely explanation for this behaviour, probably after reaching a particular level or range, however, Aw was not determined in this study to ascertain this. Texture changes in dry food products have been linked to changes in Aw as a function of temperature and humidity [21]. Loss of crispness and caking in spray dried or freeze dried sugar powders have been reported generally to begin when the Aw is raised to above 0.3 to 0.4 at room temperature, as a result of moisture pickup through the package or moisture redistribution from other micro-regions [22].

It was discovered that saltine crackers, popcorn, puffed corn curls and potato chips lost crispness if Aw exceeded 0.35-0.50 [15]. The crispness was attributed to intermolecular bonding of starch, forming small crystalline-like regions when little water was present. These regions require force to break apart, which gives the food a crisp texture. Above a certain Aw level, the water was presumed to disrupt these bonds allowing the starch molecules to slip past each other when chewed. It was observed that puffed rice cakes lost crispness at Aw just above 0.44 [23]. It has also been observed that the desirable crispiness of crackers, dry snack products such as hard cookies, crackers, potato chips, and breakfast cereals is lost if enough moisture gain occurs which makes it go above the glass transition temperature at that particular moisture [16], so it could lose crispness by gaining moisture at constant temperature or by being stored at a temperature above the glass transition temperature for that moisture content.

Water activity reaching a particular level or range and associated state or phase transitions are, therefore, probably responsible for the deformation changes observed in the cookie samples at 10 weeks of storage.

From the deformation curves in Figure 4, that of sweet potato cookie seems consistent while the control curve looks erratic. It is possible that the different additives and chemicals, as well as preservatives, included in the control formulation may be influencing this behavior whereas the test cookie was just a basic formulation devoid of these extra inclusions.

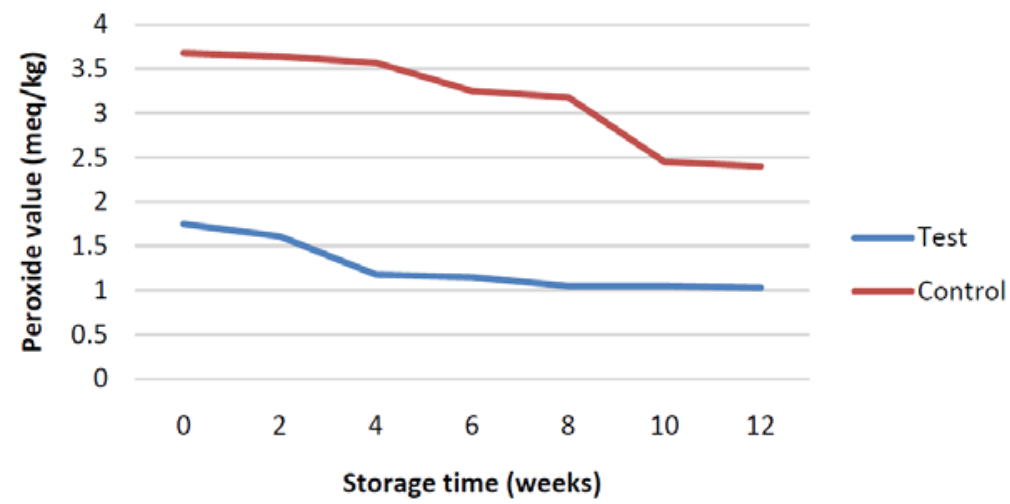

Figure 5. Changes in Peroxide value. 
The Peroxide Value (PV), in meq of oxygen peroxide per kg of sample oil and changes during the 12 week storage period are presented in Figure 5. Peroxide value is an indication of oxidative rancidity and quality deterioration in the samples. As storage continued, the values decreased from 3.68 to2.40 meq in the control and from 1.75 to 1.03 meq in the test sample. The observed decrease could probably be due to minimal moisture gain in the cookies which did not promote lipolysis of fat and the resulting rancidity, though some researchers [24] reported an increase in PV of soft dough wheat cookies during storage and stressed the need for PV analysis to be done early on oxidation, in order to detect the rather unstable hydro-peroxides formed. Values for the control were much higher than for the test sample, however, all values recorded were well below the maximum acceptable limit of 10meq specified [25]. This is a pass for the samples. In addition, no off odour or aroma was perceived or detected.

\section{Conclusion}

The results from this study have shown that sweet potato cookies are comparable in quality and behaviour to conventional wheat cookies during a storage period of twelve weeks at tropical ambient conditions, thus indicating the possible potential of sweet potato flour as a suitable alternative to wheat in cookie production. Moisture content of cookie, appropriate packaging as well as storage environment conditions are crucial areas of intervention for optimal keeping quality and shelf stability. The adoption of sweet potato, as suggested, can enhance its increased utilization and value chain addition and ultimately save valuable foreign exchange expended on wheat importation into the country.

\section{Acknowledgements}

The authors wish to acknowledge Engrs Ojo OE and Alhassan OA of the Material Science section of FIIRO for their help in determining the sample texture.

\section{References}

[1] Okpala, L. C. and Chinyelu V. A. (2011). Physicochemical, Nutritional and Organoleptic evaluation of cookies from pigeon pea (Cajanuscajan) and cocoyam (Xanthosomasp) flour blends. Afr J of Food, Agric, Nutr and Dev 11(6): 1-13.

[2] Edema, M. O., Sanni, L. O., and Sanni, A. I. (2005). Evaluation of Maize-soybean flour blends for sour maize bread production in Nigeria. Afr. J. Biotech, 4, 911-917.

[3] Olabanji O G. (2015). Overview on wheat value Chain-wheat in Nigeria: Challenges and opportunities: A Paper presented at the 2015/2016 Pre-Season Training Workshop on wheat production, processing and utilization organized by Lake Chad Research Institute and ICARDA under SARD-SC Project, Sokoto, Nigeria, 28-29th October.

[4] FAOSTAT. (2015). Food and Agricultural Organization Statistics. Consumption and trade in cassava products. Food and Agricultural Organization Statistics FAO (2015) Trend of Cassava Production in Nigeria, from 1980-2013. http://www.fao.org/faostat/en/\#data/QC.

[5] Woolfe, J. A. (1992). Sweet Potato-An untapped food resource, Cambridge University Press. Cambridge, UK.

[6] Scott G. and Ewell P. (1993). Sweet Potato in African Food Systems. In Product Development for Root and TuberCrops Vol III -Africa. International Institute of Tropical Agriculture, Ibadan. Nigeria, 91-103.

[7] FAOSTAT. (2018). Food and Agriculture Organization of the United Nations Statistics Division. www.fao.org.

[8] Von Braun, J., de Haen, H. and Blanken, J. (1991). Commercialization of agriculture under pressure-effects on production, consumption and nutrition in Rwanda. International Food Policy Research Institute (IFPRI), Washington D.C.USA.

[9] Ayinde, F. A., Adepoju, P. A., Apotiola, Z. O. and Olaleye, N. O. (2004) Production and evaluation of the nutritive value of sweet potato flour. Proceedings of the 28th Annual Conference, Nigerian Institute of Food Science and Technology, Ibadan, 4th-7th Oct, 299,

[10] FIIRO. (2000). Bread and Confectionery baking technology. Federal Institute of Industrial Research, Oshodi Training Manual, 9.

[11] AOAC. (2005). Official Methods of Analysis. Association of Official Analytical Chemists International, 18th Edition, Maryland, USA.

[12] Antolovich, M., Prenzler, P. D. and Patsalides, E. (2002). Methods for testing anti-oxidant activity. Analyst, 127, 83-98.

[13] Manakkal R. (2020). Weight gain in cookies during storage. www.quora.com.

[14] Cosmofilms. (2015). Enhanced shelf life with speciality packaging film. Cosmo films Limited presentation. Food and Beverage News, September.

[15] Katz E. E. and Labuza T. P. (1981). The effect of water activity on the sensory crispness and mechanical deformation of snack food products. J. Food. Sci., 46, 403-409.

[16] Labuza Ted, Karl Roe, Camy Payne, Fern Panda, Theodore J. Labuza, Peter S. Labuza and Laura Krusch. (2004). Storage sta- 
bility of dry food systems: influence of state changes during drying and storage. Proceedings of the 14th International Drying Symposium, São Paulo, Brazil, Aug 22-25, Vol. A, 48-68.

[17] de Morais Mariana Patricio, CaliariMárcio, Nabeshima Elizabeth Harumi, Batista Jaqueline Eduarda Rodrigues, Campos Maria Raquel Hidalgo, Soares Junior ManoelSoares. (2018). Storage stability of sweet biscuit elaborated with recovered potato starch from effluent of fries industry. Food Sci. and Tech, Campinas, 38(2): 216-222.

[18] Nielsen A. C. (1979). Product and package performance-The Consumers View. A.C. Nielsen Co, IL, USA.

[19] Mandala IG, Ioannou CA and Kostaropoulos AE. (2006). Textural attributes of cassava biscuit-Effect of relative humidity on their quality. Int J of Food Sci and Tech DOI: 10.1111/j.1365-2621.2005.01092.X.

[20] Sahni Prashant. (2017). IntJ of Pure and Applied Biosci. DOI: 10.18782/2320-7051. 4075.

[21] Saltmarch M. and Labuza T. P. (1980). Influence of relative humidity on the physico chemical state of lactose in spray-dried sweet whey powders. J. Food. Sci., 45, 5, 1231-1236.

[22] Downton G. E., Flores-luna J. L. and King C. J. (1982). Mechanism of stickiness in hygroscopic armophous powders. Ind. Eng. Chem. Fundamentals, 21, 447-451.

[23] Hsieh F., Hu L., Huff H. E. and Peng I. C. (1990). Effects of water activity on textural characteristics of puffed rice cake. Lebensmittel Wissenschaft und Technologie, 23, 6, 471-473.

[24] Chugh B., Singh G. and Kumbhar B. K. (2015). Studies on the Optimization and Stability of Low-Fat Biscuit using Carbohydrate-Based Fat Replacers. Int J of Food Properties, 18:1446-1459.

[25] SON. (2000). Nigerian Industrial Standards. Standards Organization of Nigeria Publication. Lagos, Nigeria, 5. 